\title{
Culturally Responsive Assessment of Life Science Skills and Abilities: Development, Field Testing, Implementation, and Results
}

\author{
Robert H. Zimmerman, Ph.D., and C. June Maker, Ph.D., Litt.D., University of Arizona \\ Fahad Alfaiz, PhD, King Saud University
}

Zimmerman, R. H., Maker, C. J., \& Alfaiz, F. S. (2020). Culturally responsive assessment of life science skills and abilities: Development, field testing, implementation, and results. Journal of Advanced Academics. 31(3), 329-366. DOI: 10.1177/1932202X20923981

\section{Author Note}

Correspondence concerning this article should be addressed to Robert H. Zimmerman. Email: rhzimmer@hotmail.com

This research was supported by the National Science Foundation, Grant \#1321190, Cultivating Diverse Talent in STEM, PI, Uwe Hilgert and CoPIs, C. June Maker, Frans Tax, and Martha Lindsey, University of Arizona, and Harold Begay, Tuba City Public Schools, and approved by a Native American Research Review Board, \#NNR-13.166. We acknowledge that there is no conflict of interest related to this research. 


\begin{abstract}
A research team consisting of educators of gifted students, a scientist, and experts in measurement developed a performance-based assessment of life science skills and abilities. Five high schools in the southwestern United States were the settings for field testing and implementation. Five levels of ratings were given: Unknown, Maybe, Probably, Definitely, and Wow. The majority of student scores were in the maybe and probably categories. Twenty three students [M2\} were selected for participation in science laboratories at an R1 university along with twenty students [M1] selected by conventional means. M1 and M2 students had very similar scores for six of the nine attributes measured. The performance-based assessment has the potential to identify and nurture exceptionally talented high school students across all demographic groups.

Keywords: exceptional talent, life science assessment, creative problem solving, STEM, performance-based assessment
\end{abstract}




\section{Culturally Responsive Assessments of Life Science Skills and Abilities: Development, Field Testing, Implementation, and Results}

The complexities and challenges in our world have increased, and creative minds in science, technology, engineering, and mathematics (STEM) are important to solve our world's problems. "Science education is crucial for boosting a more critical and democratic citizenship able to deal with current complex socio-environmental challenges in responsible ways.” (Heras \& Ruiz-Mallén, 2017, p. 2482) Problems the earth experiences such as ocean acidification and pollution can be stopped or reversed only by creative problem solvers in different fields. In education, engaging students in science topics, employing higher level thinking skills in science curricula, and preparing students to become creative problem solvers are goals of science education reformers (DeHaan, 2009). However, ways to promote creative problem solving in science are not broadly known or used (DeHaan).

Scientists in the United States have called for a sustained effort to develop STEM innovators (National Science Board [NSB], 2010, p. vii). One of their most important recommendations was to identify and nurture a variety of talents across all demographic groups of students. Although improvements have been seen in academic gaps between ethnic groups, these disparities by race, ethnicity, and gender in test scores, degree attainment, and employment still exist (Gonzalez \& Kuenzi, 2012). Researchers agree that ethnicity gaps still exist in science achievement (Bacharach, Baumeister, \& Furr, 2003; Miller, 2004; Kohlhaas, Lin, \& Chu, 2010; Plucker, Buroughs, \& Song, 2010; Lin, 2014; Quinn \& Cooc, 2015). Socioeconomic and racial/ethnic achievement gaps in reading and math have been shown to be large at school entry 
and remain consistent across schooling (Reardon, \& Portilla, 2016; von Hippel, Workman, \& Downey, 2018).

The differences in ethnicity are not the only factors that have contributed to academic achievement gaps. The variance of socioeconomic (SES) levels has had a vital role in students’ achievement (Duncan \& Murnane, 2014). Parents from high and middle SES levels have tended to spend more money on enrichment activities and educational services than have low SES parents. They also have spent more time on their children's education than parents of low SES children (Oakes, Lipton, Anderson, \& Stillman, 2013). The decrease in yearly income of low SES families has reduced the probability that their children can participate in extracurricular or other educational activities that cost money. In contrast, the annual income of high and middle SES families has increased since the 1970s (Duncan \& Murnane, 2014). For these reasons, development of an assessment appropriate for students from low SES levels is important.

Achievement gaps were reviewed by Subotnik, Olszewski-Kubilius, \& Worrell (2011). They concluded that educational malnourishment (Coleman, 2005), (e.g. lack of access to supplemental educational programs and other educational tools including technology, poverty, cultural and language differences), and psychosocial factors (e.g. intersection of students’ personal and social identities) were responsible for the gap in achievement among ethnic groups. Poverty was the most significant variable.

Science educators recognize these limitations. Most researchers measure student achievement by intelligence tests such as the Scholastic Aptitude Test (SAT), and state achievement tests, which include mainly items measuring memory and analytical abilities (Sternberg, 2010). The aptitude tests originally consisted of two domains, verbal and quantitative, but recently an essay was added. A number of researchers have found that when 
these tests and grades are used for identifying exceptional talent the diversity of students recognized is limited (Clasen, Middleton, \& Connell, 1994; Ford, 1998, 2006; Van Tassel-Baska, 2002; McCoach \& Siegle, 2003; Ford \& Whiting, 2006). Students of color often have lower scores than White students on multiple-choice tests (Klein, Jovanovic, Stecher, McCaffrey, Shavelson, Haertel, \& Comfort, 1997). Importantly, other assessments provide information that multiple-choice tests do not (AAAS, 2017). In addition, if one examines multiple choice testing from the perspective of the types of problems to be solved (Getzels \& Csikszentmihalyi, 1967, 1976; Maker \& Schiever 2005, 2010), the tests have only closed problem types with no creative problem-solving component. They are typified by clearly defined problems, specified methods, and right answers. Assessments that include semi-open and open-ended problem types will enable the assessment of creativity (Maker \& Schiever, 2010), which several researchers have found will increase the possibility of discovering exceptional talent in culturally and linguistically diverse and low-income students (Guignard, Kermarrec, \& Tordjman, 2016; Sarouphim, 2001, 2002; Sarouphim \& Maker, 2010; Sternberg 2010).

Woolfolk (2013) defined performance-based assessments as any form of assessment in which students do activities and produce products to evaluate their higher-level thinking abilities. Performance-based assessments have been considered a method for narrowing the differences in scores among diverse cultural and economic groups because students can show their understanding of scientific principles and their ability to create solutions during hands-on activities (Klein et al., 1997; Neil \& Medina, 1989). This type of assessment enables a holistic evaluation of the performance of an individual student in the life sciences. Therefore, we used a performance-based assessment to measure the skills and abilities of students in the life sciences. 
Methods such as performance-based assessments used to compare ethnic groups that included creative potential have been conducted, but are not generally used to identify exceptional talent (Sternberg, 2010). Several educators have found that inclusion of creativity decreases the gap in scores (Guignard, Kermarrec, \& Tordjman, 2016; Sarouphim, 2001, 2002; Sarouphim \& Maker, 2010; Sternberg 2010). For example, during the development of The Discovering Intellectual Strengths and Capabilities while Observing Varied Ethnic Responses (DISCOVER) project no significant differences were found in creative problem-solving and the percentage of students identified as gifted among different cultural groups when a performancebased assessment that included creative problem solving was used to identify exceptionally talented students (Sarouphim, 2001, 2002; Sarouphim \& Maker, 2010; Maker, 2019a).

"DISCOVER is a standardized performance-based assessment that includes tasks which increase progressively in complexity and openness.” (Sarouphim \& Maker, 2010, p. 48) Performancebased assessments have been more effective in measuring high level thinking skills such as applying, evaluating, and synthesizing information to solve complex problems (Dikli, 2003; The National Center for Fair and Open Testing [NCFOT], 2007, 2012; Resnick \& Resnick, 1992).

Factors such as motivation, effort, and creativity are not included in traditional methods of assessment (Maker, 1996, 2005, 2019a; Renzulli, 1978). Motivation or task commitment is a focused form of motivation (Renzulli, 1986) and a component of creativity (Amabile, 1996). Although long-term motivation and task commitment (effort) cannot be observed during a performance-based assessment (Sternberg, 1999; Renzulli, 1978), task motivation can be. Amabile (2013) defined task motivation as "the intrinsic motivation to engage in the activity out of interest, enjoyment, or a personal sense of challenge." (p. 135) In the DISCOVER assessments observers were asked to share their perceptions of the performance of the students in their 
groups, which often included statements about motivation. Task motivation was incorporated into the life science assessment observer's form by including behaviors to observe that were examples of task motivation (e.g., involved in task, continuously working, doesn't want to quit even when others have finished).

To develop the new assessments a research team was created. An education researcher with experience in developing K-12 performance-based assessments; a scientist versed in ecology and problem-based learning; a K-12 teacher with 35 years' experience in classrooms, education of exceptionally talented students, and development of performance-based assessments; and a post-doctorate fellow with experience in science teaching and assessment formed the core of the assessment development team. Several graduate students in education also were involved in developing the assessment. Two culturally responsive assessments in the life sciences were developed by the research team: (a) a life science (performance based) assessment that was a measure of a student's knowledge from their interactions with their surroundings and their life experiences (first-order knowledge as defined by Gardner [1992], and (b) a concept map (paper pencil task) assessment that measured what students learn in school (mainly secondorder knowledge as defined by Gardner) (Maker \& Zimmerman, 2019). In this paper we present the development, field testing, implementation, and results of the life science performance-based assessment.

\section{Creative Problem Solving in Life Science}

Creativity in a domain such as life science has three components (Amabile, 1983, 1996, 2013), domain-relevant skills, creativity-relevant processes, and task motivation. Domainrelevant skills are foundations for performance in a given domain, which has three components: (a) innate cognitive abilities, (b) innate perceptual and motor skills, and (c) formal and informal 
education. Intellectual and personal characteristics of creative individuals are reflected in creativity-relevant processes. For example, training, experience in idea generation, and personality characteristics are important.

The need to include the strengths and creative abilities of students from minority groups has increased because the demographics of minority groups in the U.S. has changed over the years (Carter \& Darling-Hammond, 2016). For example, the percentage of students of color has increased from 22\% in 1972 to $43 \%$ in 2007. By 2050, almost 50\% of young people under the age of 18 will be from minority groups (Carter \& Darling-Hammond, 2016). This demographic change means that more talented and creative young people will be overlooked if we rely only on standardized, multiple choice achievement tests for the selection of exceptionally talented students in the STEM.

\section{Conceptual Framework}

\section{Problem Solving}

Problem solving has been considered one of the basic human cognitive processes (Wang, \& Chiew, 2010). The importance of learning how to solve any problem comes from the fact that we as individuals are exposed to a variety of challenges and circumstances about which we need to make decisions. In the school setting, posing problems to solve is a way for students to apply information they learned about a specific concept instead of simply recalling information (Elvan et al., 2010). Different explanations of problem solving have been proposed. For example, in the Theory of Multiple Intelligences, Gardner (1983) defined intelligence as the ability to solve problems. Sternberg (1985, 2005) described problem solving as involving metacomponents, performance components, and knowledge-acquisition. In the Prism Model (Maker, Alhusaini, 
Pease, Zimmerman, \& Alamiri, 2015; Maker \& Anuruthwong, 2003), problem solving was seen as the "impetus" or stimulant for general capacities and specific abilities to be expressed.

Creative problem-solving is a key component of the DISCOVER project in which observers pay attention to the problem-solving process (Sarouphim \& Maker, 2010, Maker, Zimmerman, Gomez-Arizaga, Pease, \& Burke, 2015). Sarouphim and Maker (2010) examined ethnic differences using the DISCOVER performance-based assessment for identifying gifted students from diverse ethnicities. The participants were White Americans, African-Americans, Hispanics, Native-Americans, South Pacific/Pacific Islanders, and Arabs from the United States, Bahrain, and Lebanon. Researchers concluded that all ethnic groups were well represented among identified students. By focusing on problem solving in an assessment, the procedures are aligned more closely with the curriculum.

Problem-solving was incorporated into a classroom community awareness unit for sixth grade Native American students (Reinoso, 2011). Students showed enthusiasm and involvement in developing realistic solutions to a community problem that affected all of them. They gained valuable skills in language arts, science, math, and technology, applied these skills and concepts in an integrated way, and exercised their creative problem solving abilities to propose innovative solutions to persistent problems. The teacher said "Most importantly, perhaps, they now have a clear understanding of the fact that what they learn in school will be valuable to them now and in the future regardless of the careers they choose or the circumstances of their daily lives.” (Reinoso, 2011, p. 299) Students showed their creativity and demonstrated task motivation. Motivation and learning are enhanced through the use of real problems (Savery \& Duffy, 1995; Savery, 1999). Over 10 years, a one week summer science course using problem-based learning (PBL) for Native American students was given at Northern Arizona University (Quartaroli \& 
Sherman, 2011). They determined that PBL held real promise for science teachers of middleschool and high-school native students in regular classes. Creative problem solving using PBL was an integral part of student achievement, interest and motivation in science.

\section{Theories}

The life science assessments were developed based on the following theories and research: (a) Multiple Intelligences (Gardner, 1983, 1999), (b) Successful Intelligence (Sternberg, 1985), (c) the Prism of Learning (Maker \& Anuruthwong, 2003; Maker et al., 2015), and (d) research on the social science of creativity (Amabile, 1996, 2013). The assessments also were developed as an extension of Maker and colleagues’ personal experiences with performance assessments, especially DISCOVER, and research conducted over a period of more than 25 years (Maker, 2005; Nielson, 1994; Sarouphim, 2001, 2002; Sarouphim \& Maker, 2010).

Authentic tasks. The life science assessment tasks were comparable to what scientists do: they examine, classify, and investigate life on earth. These tasks were included in theory of multiple intelligences (Gardner, 1983, 1999). One of the eight domains described by Gardner was the naturalist, which is the domain related to life science (Gardner, 1999). The core competencies he identified for the naturalist domain provided important guidance for development of the life science assessment because they are competences of life scientists: (a) observation through the five senses; (b) classifying, identifying, and collecting data in both natural and man-made environments; (c) keen observation; (d) intuitive understanding of, or interest in, the natural world; (e) accurate perception of the character of shapes, forms, and texture; and (f) comparison of the different characteristics of different species (Gardner, 1999).

Theory of Successful Intelligence and social science of creativity. Sternberg's theory includes three types of intelligence: (a) analytical, which allows a person to process information 
effectively and think abstractly; (b) creative, which allows a person to come up with new ideas; and (c) practical, which allows a person to find feasible solutions to real problems (Sternberg, 1997, 2005). Sternberg posited that certain core capacities such as memory, metacognition, and reasoning cut across different domains of intelligence, and that many core capacities were specific to the domains. He recommended that all three types be included in any analysis of intelligence. He also defined intelligence as “developing expertise”, emphasizing that intelligence is not fixed, but that it develops over time as an individual learns and incorporates this learning into her or his knowledge structure (Sternberg, 1999). Consistent with Sternberg’s theories is Amabile's work on creativity (1996, 2013), in which she has found that three components are necessary for creativity to be expressed: domain-specific skills and knowledge, creativity-relevant processes that cut across domains, and task motivation or passion for the task or the problem being solved.

Prism of Learning. Maker and Anuruthwong (2003) developed the Prism of Learning, which shows how problem solving and the aspects of learning situations are related to the development and expression of gifts, talents, and creativity through different human abilities. They integrated their previous experiences with the theories and research of Amabile (1996, 2013), Gardner (1983, 1999), and Sternberg (1997, 1999, 2005). Scientific ability in the Prism of Learning provided the definition for the life science abilities being assessed:

“Scientific/Naturalistic abilities include observing, identifying, describing, classifying, studying, and explaining natural phenomena.” (Maker et al., 2015, p. 92)

\section{Assessing Problem Solving}

Although problem solving is a key concept in the theories, an operational definition of problem solving was not presented by authors other than Maker and Anuruthwong (2003). When 
developing the performance-based life science assessment, we used the problem continuum proposed by Getzels and Csikszentmihalyi (1967, 1976), modified by Maker and Schiever (2005, 2010) and presented by Maker and Anuruthwong as the framework. In the problem continuum, problems range from closed to open-ended, and a solver can create possible solutions to a problem based on information he or she has. For example, in the closed type, the solver is given only the problem and the method to solve it, so the solver's only task is to generate the one correct solution to the problem. In open-ended problems, the solver defines or chooses a problem, decides on a method to solve it, and creates a solution. No correct solution is specified or expected. The first type (closed) is designed to assess knowledge and skills, and the last type (open-ended) is designed to assess creativity (Maker, 2019a). The initial life science assessment tasks included a closed problem (cut flower exploration), a semi-open problem (classifying flowers or insects) and an open-ended problem (creating an ecosystem). The life science assessment was one of six assessments used to identify exceptionally talented students in STEM.

\section{First and Second Order Knowledge}

First-order knowledge (knowledge gained from experience) and second-order knowledge (knowledge developed in school) (Gardner 1992) were part of the conceptual framework when developing and implementing all of the new assessments. The life science assessment involved hands-on tasks to measure of first-order knowledge: life science abilities as described by Gardner (1999) as the naturalist, and the scientific abilities in the Prism Model (i.e., description of flower, sorting of flowers or insects, and ecosystem design). Performance-based assessments are appropriate methods to measure first order knowledge and often are more engaging than paperand-pencil assessments. More detailed information about the conceptual framework of the assessments can be found in another publication Maker (2019a). 
The life science assessment was developed to enable observers to see the students’ problem-solving ability, how they made inferences, how they organized natural objects (flowers and insects), and how they presented the interdependencies, interactions, and connections among natural phenomena by making an ecosystem of their own choice. These are the skills and tasks of life scientists when they examine real world phenomena and relationships among organisms.

\section{Development, Field Testing, and Revision}

The assessment was developed through an iterative process similar to that described by Ruiz-Primo (2009) that was modified from the assessment square proposed by Ruiz-Primo and colleagues (Ruiz-Primo, 2003, 2007; Shavelson, Ruiz-Primo, Li, \& Ayala, 2002). The assessment square had four components, one at each corner: construct, observation, assessment, and interpretation. Using conceptual, logical, and empirical analysis, the model was used to develop and validate the life science assessment (Ruiz-Primo, Shavelson, Li, \& Schultz, 2001; Yin, 2005). An in-depth explanation of this process is included in another publication (Maker, 2019a). Each task was designed to (a) assess different types of problem solving, (b) include core competencies of the ability being assessed, (c) be engaging and developmentally appropriate, (d) include first-order knowledge, and (e) elicit observable behaviors that demonstrate different levels of ability and task motivation.

\section{Method}

The life science assessment was created by the research team as part of the Cultivating Diverse Talent in STEM (CDTIS) project. Our goal was to identify and cultivate exceptional talent in STEM based on a new definition of exceptional talent in STEM: “ Exceptional talent in STEM has two essential components: (a) a highly integrated and interconnected knowledge structure; and (b) the ability and willingness to solve a variety of types of problems, from well- 
structured and known to ill-structured and novel, in science, technology, engineering, and mathematics in the most effective, efficient, original, or economical ways." (Maker, 2019a) The project was a collaboration between (a) faculty members at an R1 University in the Southwestern USA and (b) educators from three public schools. Six assessments were included in the identification of students with exceptional talent in STEM: (a) math problem solving (Bahar \& Maker, 2019), (b) spatial analytical performance assessment (Maker, 2019b), (c) physics concept map (Maker \& Zimmerman, 2019), (d) mechanical-technical performance assessment (Alfaiz, Pease, \& Maker, 2019), (e) life science concept map (Maker \& Zimmerman, 2019), and (f) the life science performance assessment. These six assessments were in three domains, math, physical sciences and life sciences, and were measures of students' domain-specific and creativity-relevant abilities (Amablie, 2013).

\section{Development}

State Science Standards for grades 9 to 12 provided the framework for the development of the life science assessment tasks. Specifically, we addressed the concepts and problem-solving activities from the life science and the science in personal and social perspectives strand, section Changes in the Environment.

Four task were designed to assess the scientific abilities defined in the Prism model: three problem types ranging from closed to semi-open and open, and first- order knowledge. The first task was a two-minute warm-up, using a cut flower, to stimulate memory of life science concepts. Each observer held up a flower and asked the students at his or her table to examine the flower and describe what characteristics of the flower they noticed.

The second task was to examine a cut flower for 10 minutes. It was a closed problem type to assess keen observation and perception of the character of shapes, forms, and texture. The 
observers gave the students instructions about how to inspect the flower and note its characteristics. They could dissect the flower to examine its parts. Magnifying glasses were provided for closer examination of the flower. When students completed the task, they were asked "What did you notice?” After they answered this question, they were asked "What else did you notice?” Their responses were audio recorded.

The third task was to group flowers according to the similarity of their characteristics. It was a semi-open problem type to assess competencies of scientists: (a) accurate perception of characteristics of shape and form, and (b) comparison of the different characteristics of different species (Gardner, 1999). The flower sort consisted of 18 numbered picture cards. The flowers were native to the local area, the southwestern United States, and the pictures selected showed the characteristics of the flower and the attributes of the leaves and stems (Figure 1). The observer instructed students to put the cards together in groups based on their similarities, and to record the number on the cards they decided were similar in some way in a circle on a worksheet; starting with Group A (Figure 2). Students made as many groupings as they wanted to and used the cards as many times as needed. Additional worksheets were available. The worksheets had a box above each circle where the students named each group. When each student was finished, he or she was interviewed individually and asked "How are the flowers in group [A] alike?” The response was audio recorded and written notes were taken. After students described group A, they continued with the next group. The process was repeated for each of the groups until the student described all of the groups. Thirty-five minutes were allotted for this task.

The fourth task was an open-ended problem type in which students examined 18 insect pictures. The students organized the insects in a large circle on one piece of paper rather than as 
in Task 3. Insect pictures were downloaded from the internet, occurred in or were similar to species found in the southwestern United States, and demonstrated the diversity in morphology and structure of insects (Figure 3). Students examined the characteristics of the insects and described their relationship to other insects by putting similar insects together and then showing the relationship to other groups. The purpose of this task was to assess the following competencies: (a) accurate perception of characteristics of an organism's shape and form, (b) comparison of the different characteristics of different species, and (c) intuitive understanding of the natural world (Gardner, 1999). Scientific abilities included in the Prism model (e.g., observing, identifying, describing, classifying, and explaining natural phenomena) (Maker et al., 2015) also were assessed with this activity. Thirty-five minutes were allotted for this task.

Detailed instructions were developed so the observers could follow a stepwise method of implementing the cut flower and flower sort task. A worksheet was developed that had a comprehensive list of student behaviors to observe as they carried out the task: motivation (e.g., involved in task, continuously working, showed enjoyment), and problem solving (e.g., organized materials). The observer also had a list of plant characteristics and important plant structures (e.g., narrow petals, shape and size, toothed leaves) that could be checked during the interview with the students and when listening to the audio recording.

Four observers were involved in the field test. Students, in groups of 3 to 5, sat around a table with one observer. Having small groups of students with one adult was part of the learning environment so the assessment was similar to a classroom situation; students worked individually and explained their results individually to an observer. 
Participants. Field tests were conducted four times at four partner high schools over a period of one month. Sixty-two high school seniors participated in the assessment. They and their parents signed Institutional Review Board approved assent and consent forms that included an explanation of the assessment. The number of students in these schools ranged from 94 to 2245, and more than $71 \%$ received free or reduced-price lunches. In school A, the student makeup was 83.4\% Hispanic; 5.0\% American Indian; 0.7\% Asian; 3.7\% Black; 7.0\% White; and 0.3\% Pacific Islander. In schools B and C, all students were American Indian, and in school D, 97\% of the students were American Indian and 3\% were White. The schools were located in poverty areas with an unemployment rate that ranged from $7.7 \%$ to $45.8 \%$.

Field Test 1. The flower exploration, flower sort, and insect task were included in Field Test 1 . The assessment was conducted at School B with 18 seniors. In the beginning of the field test, the observers led the warm-up activity before introducing the flower and insect tasks.

Flower task. Each student was given a cut flower and asked to examine its characteristics. When this task was completed, students were given the flower cards to sort.

Insect task. After the flower-sorting task, students were given the insect task. When this task was completed, the observers collected all materials.

Ratings. After the assessment was completed, observers met to evaluate the students’ performance. All observers participated in decisions about all students and discussed the ratings until they all agreed, so the inter-rater reliability did not need to be checked. This rating system was used throughout the development and implementation phases.

The research team decided to change the insect task because most of the students had difficulties organizing and illustrating relationships among the insects in the big circle. Also, the insect activity did not seem to measure a student's intuitive understanding of the natural world 
adequately, but it did seem to measure the same competencies as the flower sort. It became an alternative to the flower task; students could choose either flowers or insects to sort.

Ecosystem task. This task was developed to assess the core competency of intuitive understanding of the natural world (Gardner, 1999), and the scientific ability of the Prism Model (Maker \& Anuruthwong, 2003; Maker et al., 2015). An essential part of the natural world is interconnectedness and interdependence of living and non-living things. The ecosystem task, an open-ended problem-solving activity, was a measure of this understanding.

For the ecosystems task, students were instructed to create an ecosystem of their choice by using a diagram, illustration, or model. Materials to construct their ecosystems were placed in the center of the table (e.g., colored pencils, clay, colored markers, pipe cleaners, paper, rocks), and each student was given a cardboard base and drawing paper placed on top of the base to build her or his ecosystem. After students completed this task, the observer took a picture of the ecosystems and asked individual students to tell about their ecosystems. Responses were audio recorded to minimize the effects of proficiency in the use of written language and to enable the observer to ask questions when responses were not clear. Fifty minutes were allowed for this activity.

Changes. The cut flower task was changed to examining a whole flower that included the root system to allow students a more realistic representation of the plant they were to describe. Students were asked "What are the characteristics of this plant and its flower(s)? and instructed to "Name as many characteristics as you can.” The observer instructions were changed so the students could choose between insects and flowers in the grouping task.

Field Test 2. The flower exploration, the flower and insect sort, and the ecosystem task were included in Field Test 2. It was conducted at School A with 20 seniors. The same procedure 
was used as in Field Test 1 for the warm-up activity, the whole flower observation, and the flower and insect sort. After these tasks were completed, the new task, ecosystems, was introduced. Materials were put on the table for the students to share, and observers gave instructions for creating ecosystems. After the students completed their ecosystems, the observer took a picture and asked each student to tell about his or her ecosystem. Responses were audio recorded. Fifty minutes were allowed for this activity.

Changes. The ecosystem directions were modified because observers noticed that students needed more instruction. The observers believed students would focus more on the task if they had a copy of the directions. Students were given the following instructions: (a) create a drawing, diagram, or model of an ecosystem, including your live plant, some of your plant and insect pictures, and other living and non-living things, (b) show how all the parts of your ecosystem interact, (c) this environment is of your own design, and (d) you can tell me about your ecosystem when you are ready.

Field Test 3. The next version of the assessment was tested at School C with 14 high school seniors. Three team members observed the assessment, one at each table. The procedures for administration of the assessment and rating of students’ products were the same as those for Field Test 2.

Changes. After the third field test, the warm-up activity and the plant/flower exploration were eliminated from the assessment. Only the flower/insect sort and ecosystem tasks remained. The reason for eliminating these tasks was that the students had difficulties identifying and classifying the structure and function of the plant and flower parts. They did not have the appropriate vocabulary and could not recognize different characteristics of the plant or flower. Most students were more concerned about the subjective characteristics of the flowers (e.g., they 
were dead, they were messy) than they were about the objective characteristics (e.g., plant structure and function). The observers noticed that students could demonstrate their life science abilities by sorting the flowers and insects without the warm-up and the flower and plant tasks. An assessment without these activities would also be more practical to administer.

The ecosystem directions were modified again to better assist the students. The directions were (a) you will create a representation of an ecosystem by using a diagram, illustration, or model; (b) you must include some of the flowers and insects on your cards and other living and non-living things; (c) be sure to show interactions, dependent relationships, cycles, and other important aspects of ecosystems; (d) the environment is of your own design, (e) use sticky notes to label the parts of your ecosystem, and (f) I will ask you to tell me about your ecosystem when you're finished.

Field Test 4. This version of the assessment was tested with 10 seniors at School D. Three team members observed the assessment; one at each table. All administration procedures and scoring were the same as described in Field Test 3.

\section{Scoring the Field Test Assessments}

Observers used the characteristics of flowers/insects (Figure 4), to guide their scoring of students’ groupings. Each accurate grouping was given a point. The observers also scored (a) the number of groups made (fluency), (b) number of types of groups (flexibility), (c) number of details given about titles (elaboration), and (d) number of unique responses (originality). The total number of each scoring category was summed and rated as Unknown, Maybe, Probably, Definitely, and Wow. More information about this rating system is provided in a different publication (Maker, 2019a). A space for validity notes was added so observers could comment on the scientific accuracy of the groupings. To rate ecosystems, observers used the rubric in 
Table 2. Final scoring of the students' performance in the field tests included a review of each student's audio response to the observer's questions. A description of the final scoring methods is provided in the 'Rating the Assessment' part of the Implementation section.

\section{Implementation}

\section{Participants}

The life science assessment was conducted with two groups of students, all of whom were in the year of study prior to their final year in secondary school. One group (M2) consisted of students from the four partner schools and the other group (M1) consisted of students from a variety of schools that were selected by a committee based on conventional measures of achievement: overall grade point average (GPA), teacher recommendations, and student selfstatements. Students who were exceptionally talented in STEM were chosen to participate in a special internship program in the laboratories of scientists on the campus of an R1 university.

The M2 group consisted of students from the partner schools: four schools in year 1 and three schools in year 2. A total of 307 students completed the life science assessment (Table 1). The distribution of the scoring was divided into two groups, School A, and Schools B, C, and D because the ethnic makeup of the students in schools B, C, and D was similar, but different from the ethnic makeup of students in School A. Students from School D did not participate in the study in year 2. For selection of M2 students, the results of the life science performance assessment were combined with the results of the other five assessments. Student performance on all assessments was considered. Students who scored definitely or wow on all assessments were selected first, then those with definitely or wow on 5 of the assessments, then those who scored at these levels on 4 of the assessments. If other placements were available, students with the highest scores in specific areas or overall were included. 
Although the M1 students were selected for the summer internship program by conventional methods (overall GPA, teacher recommendations, and student self-statements), to be included in the research, they were required to participate in all six of the assessments used to select the M2 participants. Their participation did not depend on their scores on these assessments.

M1 participants came from a variety of types of schools, urban and rural, and from varied ethnic and economic backgrounds. The M1 group included 8 White students, 6 Hispanic students, 1 American Indian student, and 3 Asian American students; while the M2 group consisted of 2 White students, 5 Hispanic students, 13 American Indian students, 1 African American, and 2 Asian American students. A more detailed comparison of M1 and M2 participants is presented by Maker (2019a).

\section{Description and Implementation}

Life science assessment instructions. The final instructions included (a) life science observer instructions, (b) a worksheet to analyze student assessment results (Figure 4), (c) a rubric for scoring the ecosystem task (Table 2), and (d) criteria for overall scoring of life science assessments (Figure 4). Each is described in detail in the following sections.

Flower and insect sort instructions. Instructions followed a stepwise procedure including an introduction to the assessment, a description of the task, how to fill out the worksheet about flowers or insects, and reminders about how to guide the students during the assessment. Some of the important instructions were the following:

- Tell students they can choose whether they would rather sort flowers or insects.

- Ask "Which of these flowers (or these insects) are alike in some way?” Say "Make as many groups as you can.” 
- Tell the students: "Your worksheets are organized to create groupings of flowers or insects. Each picture has a number. When a group is made, write the numbers of those pictures in the first circle, Letter A, and give that group a name. Write the name of the group in the box above the circle.”

- Walk around the table to make sure students are on task.

- Interview each student after completion of the task: Ask "How are the flowers (or insects) in group [A] alike?” Record response. Then, ask the student to describe the next group. Observers had a worksheet on which they could note student responses and how the students were performing on the task. The worksheet had an observation checklist where they could note behaviors indicating motivation: (a) involved in the task, (b) continuously working, (c) persistent on difficult tasks, (d) showed enjoyment, and (e) other. They also could list problem-solving behaviors in the large open spaces. A note on the worksheet reminded the observers that if the student's labels were lengthy and rambling they could ask the student "How can you shorten that?” Twenty-five minutes were given for the flower and insect sort activity.

Ecosystem instructions. After the first year of implementation, observers noted that many students did not understand the ecosystem task. Therefore, before the second year of implementation, an activity that would stimulate the students' thinking and memory to set the stage for developing ecosystems was developed. Before beginning the assessment, observers asked the students (a) What are some examples of ecosystems you know? (b) What are the characteristics of these ecosystems? (c) What are some of the living and non-living parts of an ecosystem? and (d) What are the relationships among these parts? The observer instructions included answers to the questions to help facilitate discussion. The discussion lasted five minutes. 
The final instructions for the ecosystem included instructions developed after Field Test 3 with the addition of the following: when the first student has completed her or his ecosystem, interview that student. Say “Tell me about your ecosystem.” Then ask the student "How are these parts of ecosystems related?” Fifty minutes were allotted for the ecosystem task.

Analysis of life science assessment results worksheet. After conducting the life science assessment, observers completed the sorting and ecosystem ratings worksheet for each student (Figure 4). The worksheet included a section for rating the fluency, flexibility, elaboration, and originality for the insect or flower sort. A key for defining the criteria and a guide to key attributes of flowers and insects was included. Important morphological and structural characteristics of each group that are frequently used in life science taxonomic keys for species identification were included on the worksheet to help the observers organize student results and assign student scores.

\section{Rating the Assessment}

Each observer listened to the audio recordings of students' interviews, wrote their responses, completed their notes about each student in the group, and assigned preliminary scores for the flower or insect task and ratings for the ecosystem task. Performance on the assessment was scored using the analysis of life science assessment results worksheet (Figure 4). When all observers completed this process, they met to discuss the students’ performance and make final decisions about students' ratings. They reached consensus on the rating to assign for each student.

Flower and insect task. The final scores for this task were based on the number of points the students received in the following areas: fluency (number of groups), flexibility (number of different types of groups), elaboration (the amount of explanation given for the similarities of 
items in a group), and originality (the uniqueness of the explanations or the types of groups). The final rating for each student included all four sub-scores, and the final ratings across the flower/insect sort were assigned by agreement among all the observers who watched students from the same school. A less subjective originality scoring method was developed and added to the section on originality. The number of times a characteristic of the flowers or insects was used by the participants to sort the flowers and insects was recorded, the frequency of each characteristic calculated, and then the characteristics that were recorded $10 \%$ or less of the time were used as the cutoff for the new originality scores. Within this range observers made three rankings and assigned points to each characteristic noticed by a student: if $6 \%$ to $10 \%$ of the students mentioned a certain characteristic, this answer was given one point; characteristics mentioned by $2 \%$ to less than $6 \%$ were given 3 points; and characteristics mentioned by less than $2 \%$ of the students were given 5 points.

Five levels of ratings were made: Unknown, Maybe, Probably, Definitely, and Wow. A student was given a rating of (a) Unknown if he or she had no flexibility or elaboration or lacked validity in the reasons for groups, (b) Maybe if he or she had low flexibility and very few elaboration or originality scores, (c) Probably if he or she had some elaboration and originality scores, (d) Definitely if he or she had good elaboration and originality scores, and (e) Wow if he or she had high fluency, flexibility, elaboration, and originality scores. All observers agreed on the ratings to assign.

Ecosystem task. The scoring system for ecosystems was similar to the flower and insect scoring system. However, the criteria to determine the rating levels were different (Table 2). For example, for a Maybe rating, the student's product was a habitat rather than an ecosystem. For a Definitely rating, the student's ecosystem needed to show interrelationships, but they did not 
need to be unique. For a Wow rating, the observers considered the uniqueness in the relationships in the ecosystem. The ecosystem rubric for each level is presented in Table 2. All observers met to assign ratings for all students who were observed that day. Information students provided when they explained their ecosystems to the observers was considered when observers made ratings.

Overall scoring. To assign an overall score for the assessment, the identification ratings for the flower or insect sort and the ecosystem were combined. For instance, if one score was one rating higher than the other, the higher score was given. If the student had Maybe [M] on one task and Probably [P] on the other, the final score was Probably [P]. If the student had Maybe [M] on one task and Definitely [D] on the other, the final score was Probably [P]. Students at each school were compared with each other, and not with students from other schools.

M1 student scoring. M1 students took the life science assessment and observers scored the results. All scoring was the same except for the method for making the final ratings of Unknown, Maybe, Probably, Definitely, and Wow. Because the M1 group was small and already selected as exceptional, a different procedure was developed for comparison: four representative examples of each of the identification ratings for the M2 flower/insect sorts were selected, and used as “markers” for the rating levels for M1 students. The same procedure was used for rating the ecosystems: four representative ecosystem pictures, combined with interview information, were selected from the M2 records for each of the rating levels. The overall ratings of M1 students' performance were completed in the same way as the overall ratings of the M2 students: The ratings on both the flower/insect sort and the ecosystems were combined to form a final rating of performance.

\section{Results}


The majority of student scores were in the maybe and probably categories (Table 3). The scores of students at Schools B and C were closer to the probably rating during year 2, which could have been due to the absence of School D. The student ratings of unknown and wow were lower than the other ratings, except for the insect/flower sort in year 2 when the number of unknown ratings was higher than the number of definitely ratings. The changes made in year 2 of the ecosystem activity did not appreciably change the percentages of definitely and wow rankings. They were $7.5 \%$ higher at schools B and C in year 2 compared to year 1, and 7.4\% lower at school A.

Examples of student ecosystems are presented in Figures 6-8. The student's ecosystem in Figure 6 was rated as unknown because the student presented a minimal description of the parts and did not show any interconnection or interdependence of its components (Table 2). The student's interview with the observer indicated that the student did not have a full understanding of an ecosystem. The student's ecosystem in Figure 7 was rated probably because the student presented some elements of the ecosystem, included living and non-living things, and connected different parts. During the interview the student demonstrated a basic understanding of an ecosystem. In the Wow example (Figure 8) the student presented the ecosystem in a unique way, using models, a picture from the flower/insect sort, and drawings. The written explanation was accurate, and the interview was detailed and showed a full understanding of the complexity of an ecosystem (Table 2).

Twenty-three M2 students and twenty M1 students were selected for the internship program during two summers (Table 4). All four partner schools had M2 students represented in the internship program. M1 and M2 participants had very similar scores for six of the nine criteria (Figure 9). The M2 students had somewhat higher average flexibility and group total 
scores than did M1 students, while the M1 students had higher originality scores than M2 students. Figure 9 is a comparison between the ranking for M1 and M2 participants for the Insect/Flower Sort, the Ecosystem, and the Identification rating.

\section{Discussion}

Field testing of the life science assessment demonstrated the need to determine the best way to assess science content using performance-based assessments and to challenge preconceived assumptions of assessment designers. The changes made by the research team during the field testing from cut flowers to flower/insect sort demonstrated that students may have little or no experience with field taxonomy that many scientists understand and use. This may be foreign to students even if they have had introductory biology and earth science courses. The flower/insect sort assessment was a way to overcome this difficulty. The focus was on first order knowledge (Gardner, 1992) and the ability to notice similarities and differences through observations (Maker \& Anuruthwong, 2003) rather than second order knowledge of taxonomies. This component of the assessment was an important way to accommodate the strengths and cultural characteristics of students from American Indian and Hispanic cultures.

The same can be said for the ecosystem assessment. The research team assumed that the students had a clear idea of the characteristics of an ecosystem; however, more guidance was necessary. The following changes were implemented: (a) a copy of the directions in Field Test 2 was given to the students; (b) more instruction on use of flower and insect pictures and components of an ecosystem was added to Field Tests 3 and 4; (c) an activity that stimulated the students' thinking and memory about ecosystems was developed and discussed with the students in year 2 of the implementation; and (d) students were asked by the observers to not only tell about their ecosystems, but also to tell how the parts of their ecosystems were related. We 
considered this to be a valuable addition, however, we did not see any significant change in the ecosystem assessment in year 2 compared to year 1.

The similarities between M2 and M1 participants on the life science assessment demonstrated that an assessment in which creativity and problem-solving are included has the potential to identify underrepresented students in the life sciences from diverse cultural, ethnic, and economic groups. The results provided a way to identify and nurture exceptionally talented student across all demographic groups as was recommended by the National Science Board (2010). Performance based assessments in STEM will provide an alternative and a complement to multiple choice tests and therefore increase the diversity of students in the sciences.

The performance-based assessment gave students the opportunity to work as a group during the ecosystem warm-up discussion, and offered them the opportunity to relate their results to their places in their communities during the interview process. Many students would rather tell an observer about how the different insects and flowers were related in an interview and tell what they incorporated into their ecosystems rather than writing about them. This aspect of the assessment also minimizes differences between students in their writing ability.

\section{Suggested Uses}

After the life science assessments were scored, they were combined with the other STEM assessments and profiles were created for classrooms, schools, and individual students. These were given to the student, the parents, and the student's teachers. The teachers were encouraged to use the results of the life science assessments to help students find opportunities to develop their strengths and plan instruction to meet students’ needs and parents (Pease, Vuke, Maker, \& Muammar, 2019). 
The performance-based life science assessment can be used in multiple ways. It can be used separately, or it can be used in combination with life science concept maps, multiple choice achievement and ability tests already being administered. Because it was developed with the goal of achieving a fair assessment of abilities across diverse cultural, ethnic, and economic groups, it can provide a way to include underrepresented students in special educational programs.

1. For special programs to develop problem solving ability and creativity, this assessment can be used as a stand-alone measure or in combination with tests of creativity.

2. The individual tasks can be used separately as in-class assessments of different knowledge and skills in life sciences. For instance, the flower and insect sorting task can be used as a pre- and post-test of the knowledge of different plant and insect characteristics as well as understanding of the basic aspects of classification systems. The ecosystem task can be used similarly, to determine students' understanding of the connectedness and interdependence of living and non-living things.

3. The performance-based assessment could be combined with existing assessments to identify students for special life science programs for exceptionally talented students because it is potentially fair to students from underrepresented groups.

4. The life science assessment can be used alone or in combination with other assessments to assess the quality of teaching in life science classrooms.

5. The life science assessment can be used in classrooms to help teachers design and differentiate their lessons to meet students’ academic needs (Hodges, 2005; Pease, et. al, 2019; Sandri, 2013; Tracy, 2015). Teachers can use these tasks to determine the strengths of their students and then design instruction to meet these needs. 
6. If students have difficulty with open-ended problem solving but can solve closed and semi-open problems easily, then the teacher can start with these problems and gradually introduce more open-ended problems to give students opportunities to think about problems in creative ways, create new methods for solving them, and generate unusual solutions (Maker \& Schiever, 2010).

\section{Research Needed}

The CDTIS research team used the life science assessment mostly with Hispanic and American Indian students because the partner schools were located in areas with a majority of students from these two groups. One of the most important future investigations needs to be with larger numbers from these two groups and with other ethnic and cultural groups, and students from high and middle SES levels to demonstrate the widespread utility of the assessments.

Research needs to be conducted to determine the inter-rater reliability and the construct, concurrent, and predictive validity of the assessment. To study inter-rater reliability, one example is to ask a team of qualified observers to rate all products already scored by a different team of observers and calculate the extent of their agreement.

To study construct validity, both qualitative and quantitative designs are appropriate. An example of a qualitative study is to ask life science teachers and teacher educators to review the products of students, including ecosystem examples, and groupings of flowers or insects, and to decide which of the products demonstrate (a) low abilities in life science and (b) high abilities in life science. Then, ask them to list the qualities of the products that distinguish between high and low abilities. The extent to which these lists of qualities match the constructs identified for the assessments is an indication of the construct validity of the assessment. 
Concurrent validity often is difficult to study because so few instruments are designed to measure creative problem solving in STEM areas. Most instruments, such as multiple-choice tests, are measures of knowledge rather than critical and creative thinking. However, if stateapproved, norm-referenced instruments are used, evidence of concurrent validity is low to moderate correlations with scores on the performance-based assessment. One paper-and pencil assessment that is similar to the life science assessment is the scientific problem-solving test designed by Sak and Ayas (2013) for middle school students. Although it is not administered in the same format, the problem-solving abilities are similar.

Because the intent of the life science assessment and the other assessments was to find students with high potential to be innovators in life sciences, studies of the predictive validity of the instruments is essential. One study has been conducted (Wu, Pease, \& Maker, 2019) in which students who were selected using the life science and other new assessments developed for the CDTIS project, and who participated in the special internship program, described their experiences in the internship and in subsequent programs at their schools. Their comments provided evidence of predictive validity because of the match between what they perceived as valuable aspects of the program and the qualities assessed with the new instruments. Other evidence was that they had set future school and career goals in STEM that reflected a desire to pursue advanced studies.

\section{Conclusion}

The performance-based life science assessment developed and implemented in this study has the potential to improve the selection of exceptionally talented high school students. It can be used separately or in combination with traditional and other nontraditional assessments to measure the strengths and creative abilities of students in STEM. We presented multiple ways in 
which it can be used in education; not just for the identification of exceptional talent in the life sciences. Further inquiry into the factors that influence the performance of culturally or linguistically diverse students in life science and ecology was recommended by Whiting and Ford (2006). Continuing to improve how exceptionally talented students are identified in the sciences is of utmost importance.

Promoting creativity among students often results in an increase in self-esteem, improved academic achievement, and acquisition of strong scientific skills (Elvan, Güven, \& Aydogdu, 2010; Kind \& Kind, 2007; Kuo, 2016; National Advisory Committee on Creative and Cultural Education [NACCCE], 1999; Sandri, 2013). The creative problem-solving component of the life science assessment will help teachers better understand the creative potential of students, and help the students increase their interest in the sciences.

The comparison between M2 and M1 participants validated the premise that assessments that include creativity and problem solving have the potential to identify underrepresented and exceptionally talented high school students in STEM. 


\section{References}

Alfaiz, F. S., Pease, R., \& Maker, C. J. (2019). Culturally responsive assessments of physical science abilities: Development, field testing, and implementation. Manuscript submitted for publication.

Amabile, T. M. (1983). The social psychology of creativity. New York, NY: Springer-Verlag New York Inc.

Amabile, T. M. (1996). Creativity in context: Update to the social psychology of creativity. Boulder, CO: Westview Press Inc.

Amabile, T. M. (2013). Componential theory of creativity. In Encyclopedia of management theory. (pp. 134-139). Los Angeles, CA: SAGE Publications, Inc.

American Association for the Advancement of Science (2017, January). Frequently asked questions. Retrieved from http://assessment.aaas.org/pages/faq

Anuruthwong, U. (2002). Exploring center: Ignition key to children’s potential and thinking. In U. Anuruthwong, S. Hiranburana, \& Piboonchoil, C. Igniting Children’s Potentials and Creativity: Proceedings of the 7th Asia-Pacific Conference on Giftedness (pp. 9293).

Bacharach, V. R., Baumeister, A. A., \& Furr, R. M. (2003). Racial and gender science achievement gaps in secondary education. The Journal of genetic psychology, 164(1), 115-126.

Bahar, K. \& Maker, C.J. (2019). Culturally responsive assessment of mathematical ability: Development, field testing, and implementation. Manuscript submitted for publication. 
Carter, L., \& Darling-Hammond, L. (2016). Teaching diverse learners (5th ed.). In D. H. Gitomer \& C. A. Bell (Eds), Handbook of research on teaching on teaching (pp. 593-637). Washington, DC: American Educational Research Association.

Clasen, D. R., Middleton, J. A., \& Connell, T. J. (1994). Assessing artistic and problem-solving performance in minority and nonminority students using a nontraditional multidimensional approach. Gifted Child Quarterly, 38(1), 27-32.

Coleman, L. J. (2005). Nurturing talent in high school: Life in the fast lane. New York: Teachers College Press.

DeHaan, R. L. (2009). Teaching creativity and inventive problem solving in science. Life Sciences Education, 8(3), 172-181.

Dikli, S. (2003). Assessment at a distance: Traditional vs. alternative assessments: The Turkish Online Journal of Educational Technology, 2(3), 13-19.

Duncan, G. J., \& Murnane, R. J. (2014). Restoring opportunity: The crisis of inequality and the challenge for American education. Cambridge, Massachusetts: Harvard Education Press.

Elvan, Ý. N. C. E., Güven, E., \& Aydogdu, M. (2010). Effect of problem solving method on science process skills and academic achievement. Journal of Turkish Science Education, $7(4), 13-25$.

Ford, D. Y. (1998). The underrepresentation of minority students in gifted education: Problems and promises in recruitment and retention. The Journal of Special Education, 32(1), 4-14.

Ford, D. Y. (2006). Desegregating gifted education: A need unmet. Journal of Negro Education, 64(1), 52-62. 
Ford, D. Y., \& Whiting, G. W. (2006). Underrepresentation of diverse students in gifted education: Recommendations for nondiscriminatory assessment (part 1). Gifted Education Press Quarterly, 20(2), 2-6.

Gardner, H. (1983). Frames of mind: The theory of multiple intelligences. New York: Basic Books.

Gardner, H. (1992). Assessment in context: The alternative to standardized testing. In B. Gifford \& M. O'Connor (Eds.), Changing assessments: Alternative views of aptitude, achievement, and instruction (pp. 77-120). Boston. MA: Springer Netherland.

Gardner, H. (1999). Intelligences reframed: Multiple intelligences for the 21st century. NY: Basic Books.

Getzels, J., \& Csikszentmihalyi, M. (1967). Scientific creativity. Science Journal, 3(9), 80-84. Retrieved from http://psycnet.apa.org/psycinfo/1967-16699-001

Getzels, J., \& Csikszentmihalyi, M. (1976). The creative vision: A longitudinal study of problem finding in art. New York: Wiley.

Gonzalez, H. B., \& Kuenzi, J. J. (2012). Science, technology, engineering, and mathematics (STEM) education: A primer. Congressional Research Service, Library of Congress.

Guignard, J. H., Kermarrec, S., \& Tordjman, S. (2016). Relationships between intelligence and creativity in gifted and non-gifted children. Learning and Individual Differences, 52, 209215.

Heras, M., \& Ruiz-Mallén, I. (2017). Responsible research and innovation indicators for science education assessment: how to measure the impact? International Journal Science Education, 39(18), 2482-2507.

Hodges, G. C. (2005). Creativity in education. English in Education, 39(3), 47-61. 
Kind, P. M., \& Kind, V. (2007). Creativity in science education: Perspectives and challenges for developing school science. Studies in Science Education, 43(1), 1-37.

Klein, S. P., Jovanovic, J., Stecher, B. M., McCaffrey, D., Shavelson, R. J., Haertel, E., Comfort, K. (1997). Gender and racial/ethnic differences on performance assessments in science. Educational Evaluation and Policy Analysis, 19(2), 83-97.

Kohlhaas, K., Lin, H. H., \& Chu, K. L. (2010). Disaggregated outcomes of gender, ethnicity, and poverty on fifth grade science performance. RMLE Online, 33(7), 1-12.

Kuo, P. H. (2016). Effects of synchronous web-based instruction on students' thinking styles and creativity. Eurasia Journal of Mathematics, Science \& Technology Education, 12(3), 609-619.

Maker, C. J. (1996). Identification of gifted minority students: A national problem, needed changes and a promising solution. Gifted Child Quarterly, 40(1), 41-50.

Maker, C. J. (2005). The DISCOVER Project: Improving assessment and curriculum for diverse gifted learners. Senior Scholars Series Monograph. Storrs, CT: National Research Center on the Gifted and Talented.

Maker, C. J. (2019a). Identifying Exceptional Talent in Science, Technology, Engineering, and Mathematics (STEM): Increasing Diversity and Assessing Creative Problem Solving. Manuscript submitted for publication.

Maker, C. J. (2019b). Culturally Responsive Assessments of Spatial Analytical Skills and Abilities: Development, Field Testing, and Implementation. Manuscript submitted for publication. 
Maker, C. J. \& Anuruthwong, U. (2003). The miracle of learning: The prism model. Proceedings of the 15th Biennial World Conference of the World Council for Gifted and Talented Students. Adelaide, Australia: World Council for Gifted and Talented Students.

Maker, C. J., \& Schiever, S. W. (2005). Teaching models in education of the gifted (3rd ed.). Austin, TX: Pro-ed.

Maker, C. J., \& Schiever, S. W. (2010). Curriculum development and teaching strategies for gifted learners (3rd ed.). Austin, TX: Pro-Ed.

Maker, C. J., Alhusaini, A. A., Pease, R., Zimmerman, R., \& Alamiri, F. Y. (2015). Developing creativity, talents, and interests across the lifespan: Centers for creativity and innovation. Turkish Journal of Giftedness and Education, 5(2), 83-109.

Maker, C. J., Zimmerman, R., Gomez-Arizaga, M. P., Pease, R., \& Burke, E. M. (2015). Developing real-life problem solving: Integrating the DISCOVER problem matrix, problem based learning, and thinking actively in a social context. In Applied practice for educators of gifted and able learners (pp. 131-168). Brill Sense.

Maker, C. J. \& Zimmerman, R. H. (2019). Concept Maps as Culturally Responsive Assessments of the Complexity and Interrelationships of Concepts in Science. Manuscript submitted for publication.

McCoach, D. B., \& Siegle, D. (2003). Factors that differentiate underachieving gifted students from high-achieving gifted students. Gifted Child Quarterly, 47(2), 144-154.

Miller, L. S. (2004). Promoting Sustained Growth in the Representation of African Americans, Latinos, and Native Americans among Top Students in the United States at All Levels of the Education System. National Research Center on the Gifted and Talented NRCGT. 
National Advisory Committee on Creative and Cultural Education (1999). Retrieved from http://sirkenrobinson.com/pdf/allourfutures.pdf

National Science Board [NSB]. (2010). Preparing the Next Generation of STEM Innovators: Identifying and Developing our Nation's Human Capital. Arlington, VA: National Science Foundation.

Neill, D. M., \& Medina, N. J. (1989). Standardized testing: Harmful to educational health. The Phi Delta Kappan, 70(9), 688-697.

Nielson, A. B. (1994). Traditional identification: Elitist, racist, sexist? New evidence. CAG Communicator: The Journal of the California Association for the Gifted, 24(3), 18-31.

Oakes, J., Lipton, M., Anderson, L., \& Stillman, J. (2013). Teaching to change the world. Boulder, CO: Paradigm Publishers.

Pease, R. Vuke, M. H., Maker, C. J., \& Muammar, O. M. (2019) A Practical Guide for Implementing the STEM Assessment Results in Classrooms: Using Strength-Based Reports and Real Engagement in Active Problem Solving (REAPS). Manuscript submitted for publication.

Plucker, J. A., Burroughs, N., \& Song, R. (2010). Mind the (Other) Gap! The Growing Excellence Gap in K-12 Education. Center for Evaluation and Education Policy, Indiana University.

Quartaroli, M., \& Sherman, F. (2011). Problem-based learning: Valuing cultural diversity in science education with Native students. Honoring our heritage: Culturally appropriate approaches to indigenous education, 57-74. Retrieved from http://jan.ucc.nau.edu/ jar/HOH/HOH-4.pdf 
Quinn, D. M., \& Cooc, N. (2015). Science achievement gaps by gender and race/ethnicity in elementary and middle school: Trends and predictors. Educational Researcher, 44(6), 336-346.

Reardon, S. F., \& Portilla, X. A. (2016). Recent trends in income, racial, and ethnic school readiness gaps at kindergarten entry. AERA Open, 2(3), 2332858416657343

Reinoso, J. L. (2011). Real-life problem solving: Examining the effects of alcohol within a community on the Navajo nation. Gifted Education International, 27(3), 288-299.

Renzulli, J. S. (1978). What makes giftedness?. Re-examining a definition. Phi Delta Kappan, 60(3), 180-184, 261.

Renzulli, J. S. (Ed.). (1986). Systems and models for developing programs for the gifted and talented. Storrs CT: Creative Learning Press.

Resnick, L. B. \& Resnick, D. P. (1992). Assessing the thinking curriculum: New tools for educational reform. In Gifford, B. R, \& O’Connor, M. C. (5th ed.). Changing assessments: Alternative views of aptitude achievement and instruction (pp. 37-76). New York, NW: Springer Science and Business Media.

Ruiz-Primo, M. (2003). A framework to examine cognitive validity. Paper presented at the meeting of the American Education Research Association, Chicago.

Ruiz-Primo, M. (2007). Assessment in science and mathematics: Lessons learned. In M. Hoepfl \& M. Lindstrom (Eds.), Assessment of Technology Education, CTTE 56th Yearbook (pp. 203-232).Woodland Hills, CA: Glencoe-McGraw Hill.

Ruiz-Primo, M. (2009). Towards a framework for assessing 21st century science skills. Paper prepared for the Workshop on Exploring the Intersection of Science Education and the Development of 21st Century Skills, National Research Council. 
Ruiz-Primo, M., Shavelson, R., Li, M., \& Schultz, S. (2001). On the validity of cognitive interpretations of scores from alternative concept-mapping techniques. Educational Assessment, 7(2), 99-141.

Sak, U., \& Ayas, M. B. (2013). Creative Scientific Ability Test (C-SAT): A new measure of scientific creativity. Psychological Test and Assessment Modeling, 55(3), 316-329.

Sandri, O. J. (2013). Exploring the role and value of creativity in education for sustainability. Environmental Education Research, 19(6), 765-778.

Sarouphim, K. M. (2001). DISCOVER: Concurrent validity, gender differences, and identification of minority students. Gifted Child Quarterly, 45(2), 130-138.

Sarouphim, K. M. (2002). DISCOVER in high school: Identifying gifted Hispanic and Native American students. The Journal of Secondary Gifted Education, 14(1), 30-38.

Sarouphim, K. M. \& Maker, C. J. (2010). Ethnic and gender differences in identifying gifted students: A multi-cultural analysis. International Education, 39(2), 42-56.

Savery, J. R. (1999). Enhancing motivation and learning through collaboration and the use of problems. In S. Fellows and K Ahmet (Eds.), Inspiring students: case studies in motivating the learner, (pp 33-42). London: Kogan Page.

Savery, J. R. \& Duffy, T. M. (1995). Problem-based learning: an instructional model and its constructivist framework. In B. Wilson (Ed.), Constructivist learning environments: case studies in instructional design (pp. 135-148). Englewood Cliffs, NJ: Educational Technology Publications.

Shavelson, R., Ruiz-Primo, M., Li, M., \& Ayala, C. (2002). Evaluating new approaches to assessing learning. CSE: Technical Report 604. Los Angeles, CA: Center for Research on Evaluation, Standards, and Student Testing/ University of California, Los Angeles. 
Sternberg, R. J. (1985). Beyond IQ: A triarchic theory of human intelligence. Cambridge: Cambridge University Press.

Sternberg, R. J. (1997). Successful intelligence: How practical and creative intelligence determine success in life. First Agency Publishing.

Sternberg, R. J. (1999). Handbook of creativity. Cambridge, United Kingdom: Cambridge University Press.

Sternberg, R. J. (Ed.). (2000). Handbook of intelligence. Cambridge, UK: Cambridge University Press.

Sternberg, R. J. (2005). The theory of successful intelligence. Revista Interamericana De Psicología/ Interamerican Journal of Psychology, 39(2), 189-202.

Sternberg, R. J. (2010). Assessment of gifted students for identification purposes: New techniques for a new millennium. Learning and Individual Differences, 20(4), 327-336.

Subotnik, R. F., Olszewski-Kubilius, P., \& Worrell, F. C. (2011). Rethinking giftedness and gifted education: A proposed direction forward based on psychological science. Psychological science in the public interest, 12(1), 3-54.

The National Center for Fair and Open Testing (2007). Multiple-choice tests. Retrieved from http://www.fairtest.org/multiple-choice-tests

The National Center for Fair and Open Testing [NCFOT], 2012 What's Wrong With Standardized Tests? Retrieved from https://www.fairtest.org/facts/whatwron.htm Tracy, B. (2015). Creativity and problem solving. New York, N.Y: AMACOM. Van Tassel-Baska, J. (2002). Planning effective curriculum experiences for gifted learners. Understanding Our Gifted, 15(1), 6-8. 
von Hippel, P. T., Workman, J., \& Downey, D. B. (2018). Inequality in reading and math skills forms mainly before kindergarten: A replication, and partial correction, of "Are schools the great equalizer?”. Sociology of Education, 91(4), 323-357.

Wang, Y., \& Chiew, V. (2010). On the cognitive process of human problem solving. Cognitive Systems Research, 11(1), 81-92.

Woolfolk, A. (2013). Educational psychology. (12th ed.). Upper Saddle River, NJ: Pearson.

Wu, I. C., Pease, R., \& Maker, C. J. (2019). Students’ perceptions of a special program for developing exceptional talent in STEM. Journal of Advanced Academics, 30(4), 474499.

Yin, Y. (2005). The influence of formative assessments on student motivation, achievement, and conceptual change. Unpublished doctoral dissertation, Stanford University, Stanford, California, USA. 
Table 1

Number of students in the year of study prior to their final year in secondary school who participated in the life science assessment by school, gender, and ethnicity

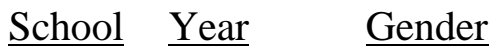

\begin{tabular}{|c|c|c|c|c|c|c|c|c|}
\hline & & Female & Male & $\begin{array}{c}\text { Native } \\
\text { American }\end{array}$ & $\begin{array}{l}\text { White not } \\
\text { Hispanic }\end{array}$ & $\begin{array}{l}\text { African } \\
\text { American }\end{array}$ & Hispanic & $\begin{array}{l}\text { Asian and } \\
\underline{\text { Pacific }} \\
\text { Islander }\end{array}$ \\
\hline \multirow[t]{2}{*}{ A } & 1 & 38 & 39 & 4 & 4 & 3 & 64 & 2 \\
\hline & 2 & 54 & 46 & 3 & 11 & 6 & 77 & 3 \\
\hline \multirow[t]{2}{*}{ B } & 1 & 10 & 10 & 20 & 0 & 0 & 0 & 0 \\
\hline & 2 & 14 & 10 & 23 & 0 & 0 & 0 & 1 \\
\hline \multirow[t]{2}{*}{$\mathrm{C}$} & 1 & 5 & 5 & 10 & 0 & 0 & 0 & 0 \\
\hline & 2 & 12 & 5 & 17 & 0 & 0 & 0 & 0 \\
\hline $\mathrm{D}$ & 1 & 35 & 24 & 59 & 0 & 0 & 0 & 0 \\
\hline Total & & 168 & 139 & 136 & 15 & 9 & 141 & 6 \\
\hline
\end{tabular}




\section{Table 2}

Ecosystem rubric criteria for each level

\begin{tabular}{|c|c|}
\hline Rating level & $\begin{array}{c}\text { Criteria for rating levels } \\
\text { The diagram, illustration, or model and/or the explanation }\end{array}$ \\
\hline Unknown (U) & - Includes a description of the separate parts \\
\hline Maybe (M) & $\begin{array}{l}\text { - Has important elements of a habitat } \\
\text { - Includes living and non-living things }\end{array}$ \\
\hline Probably (P) & $\begin{array}{l}\text { - Has a cycle or cycles, but they are not complete } \\
\text { - } \text { Is more than a habitat for one plant or animal } \\
\text { - Includes some dependencies } \\
\text { - May include some interactions, but they are not complete } \\
\text { - Has parts of a food chain, but may not be complete }\end{array}$ \\
\hline Definitely (D) & $\begin{array}{l}\text { - Shows interrelationships } \\
\text { - } \quad \text { Demonstrates understanding of complete cycle(s) } \\
\text { - Shows a complete and accurate food chain } \\
\text { - Shows dependencies } \\
\text { - Shows interactions }\end{array}$ \\
\hline Wow (W) & $\begin{array}{l}\text { - Uniqueness of expressing relationships } \\
\text { - Complexity } \\
\text { - Uniqueness of design }\end{array}$ \\
\hline
\end{tabular}

Note: Each higher level includes characteristics of the level below it. 
Table 3.

Ratings of Life Science Assessments (number and percent of total) for the Insect/Flower Sort, Ecosystems, and Identification

\begin{tabular}{|c|c|c|c|c|c|c|c|}
\hline \multicolumn{2}{|c|}{ Year } & \multicolumn{3}{|c|}{ Schools B, C, and D } & \multicolumn{3}{|c|}{ School A } \\
\hline \multirow{6}{*}{1} & Rating & Insect/Flower & Ecosystem & Identification & Insect/Flower & Ecosystem & Identification \\
\hline & Unknown & $1(1.12)$ & $11(12.36)$ & $1(1.12)$ & $5(6.49)$ & $3(3.90)$ & $2(2.60)$ \\
\hline & Maybe & 45 (50.56) & 35 (39.33) & 35 (39.33) & 48 (62.34) & $44(57.14)$ & $41(53.25)$ \\
\hline & Probably & $33(37.07)$ & $28(31.46)$ & 38 (42.69) & 15 (19.48) & 15 (19.48) & $22(28.57)$ \\
\hline & Definitely & $10(11.23)$ & 14 (15.73) & 14 (15.73) & $6(7.79)$ & 12 (15.58) & 10 (12.99) \\
\hline & Wow & 0 & $1(1.12)$ & $1(1.12)$ & $3(3.90)$ & $3(3.90)$ & $2(2.60)$ \\
\hline \multirow{6}{*}{2} & & \multicolumn{3}{|c|}{ Schools B and C } & \multicolumn{3}{|c|}{ School A } \\
\hline & Unknown & $11(26.82)$ & $3(7.32)$ & $1(2.44)$ & $14(14.0)$ & $2(2.0)$ & $0(0.0)$ \\
\hline & Maybe & $14(34.15)$ & 20 (48.78) & 17 (41.46) & $42(42.0)$ & $53(53.0)$ & $40(40.0)$ \\
\hline & Probably & $13(31.71)$ & 8 (19.51) & $14(34.15)$ & $40(40.0)$ & $33(33.0)$ & $48(48.0)$ \\
\hline & Definitely & $3(7.32)$ & 8 (19.51) & 8 (19.51) & $4(4.0)$ & $11(11.0)$ & $12(12.0)$ \\
\hline & Wow & 0 & $2(4.88)$ & $1(2.44)$ & 0 & $1(1.0)$ & $0(0.0)$ \\
\hline
\end{tabular}




\section{Table 4.}

Average Life Science Scores for the $M 1(N=20)$ and $M 2(N=23)$ participants

$$
\underline{\text { Indicator Scores for each Attributes }}
$$

\begin{tabular}{|c|c|c|c|c|c|c|c|c|c|}
\hline$\frac{\text { Participant }}{\text { group }}$ & Fluency & Flexibility & Elaboration & Originality & $\frac{\text { Group }}{\text { Total }}$ & $\begin{array}{l}\text { Group } \\
\text { Rating }\end{array}$ & $\frac{\text { Ecosystem }}{\underline{\text { Rating }}}$ & $\frac{\text { Identification }}{\text { Rating }}$ & $\stackrel{\mathrm{New}}{\text { Originality }}$ \\
\hline M1 & 15.45 & 8.80 & 2.70 & 2.30 & 29.20 & 3.00 & 3.35 & 3.35 & 3.90 \\
\hline M2 & 15.95 & 10.41 & 3.05 & 1.64 & 30.95 & 3.23 & 3.23 & 3.50 & 3.95 \\
\hline
\end{tabular}




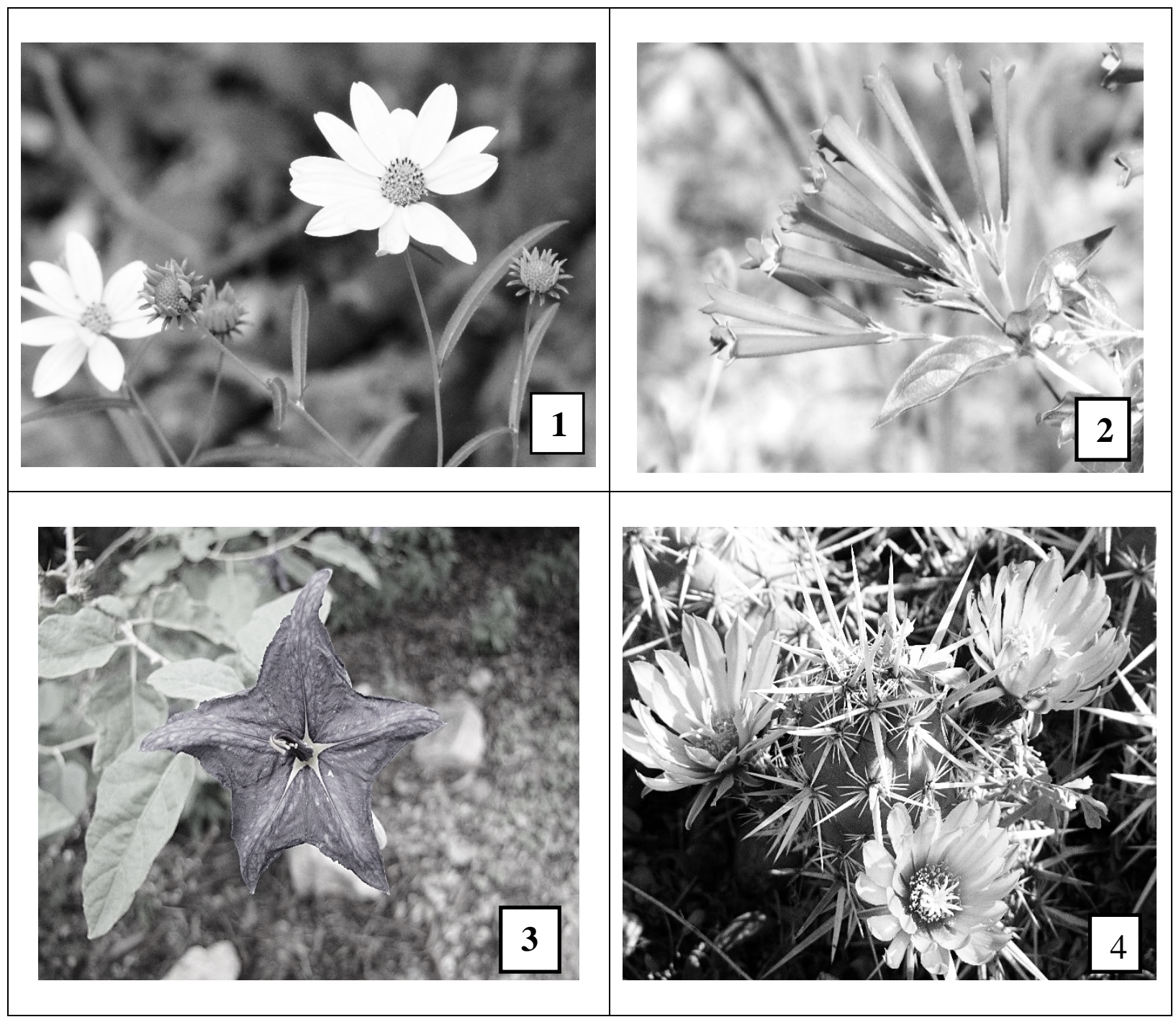

Figure 1. Examples of flower picture cards used in the life science assessment activity 


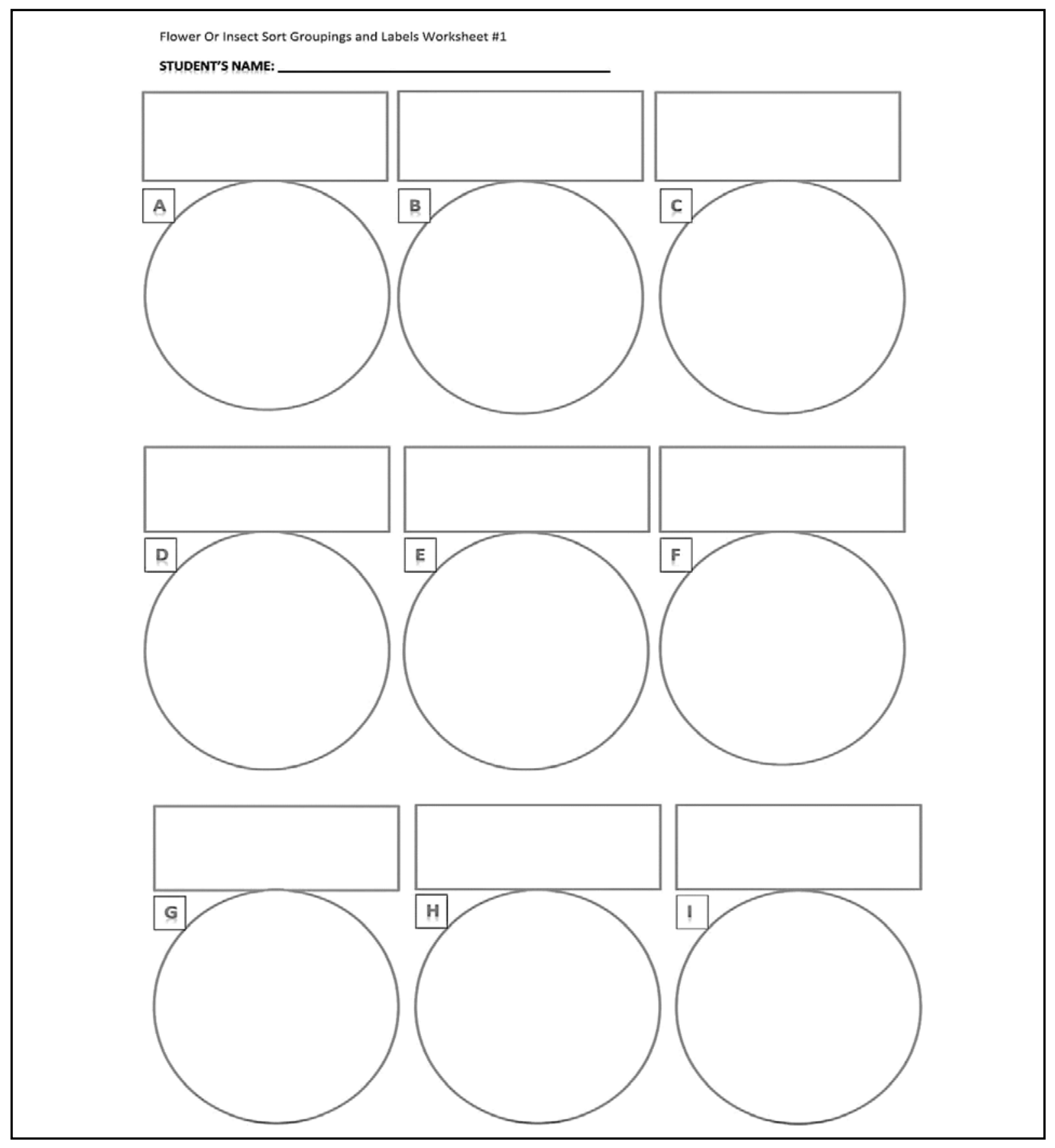

Figure 2. Worksheet to classify flowers or insects 


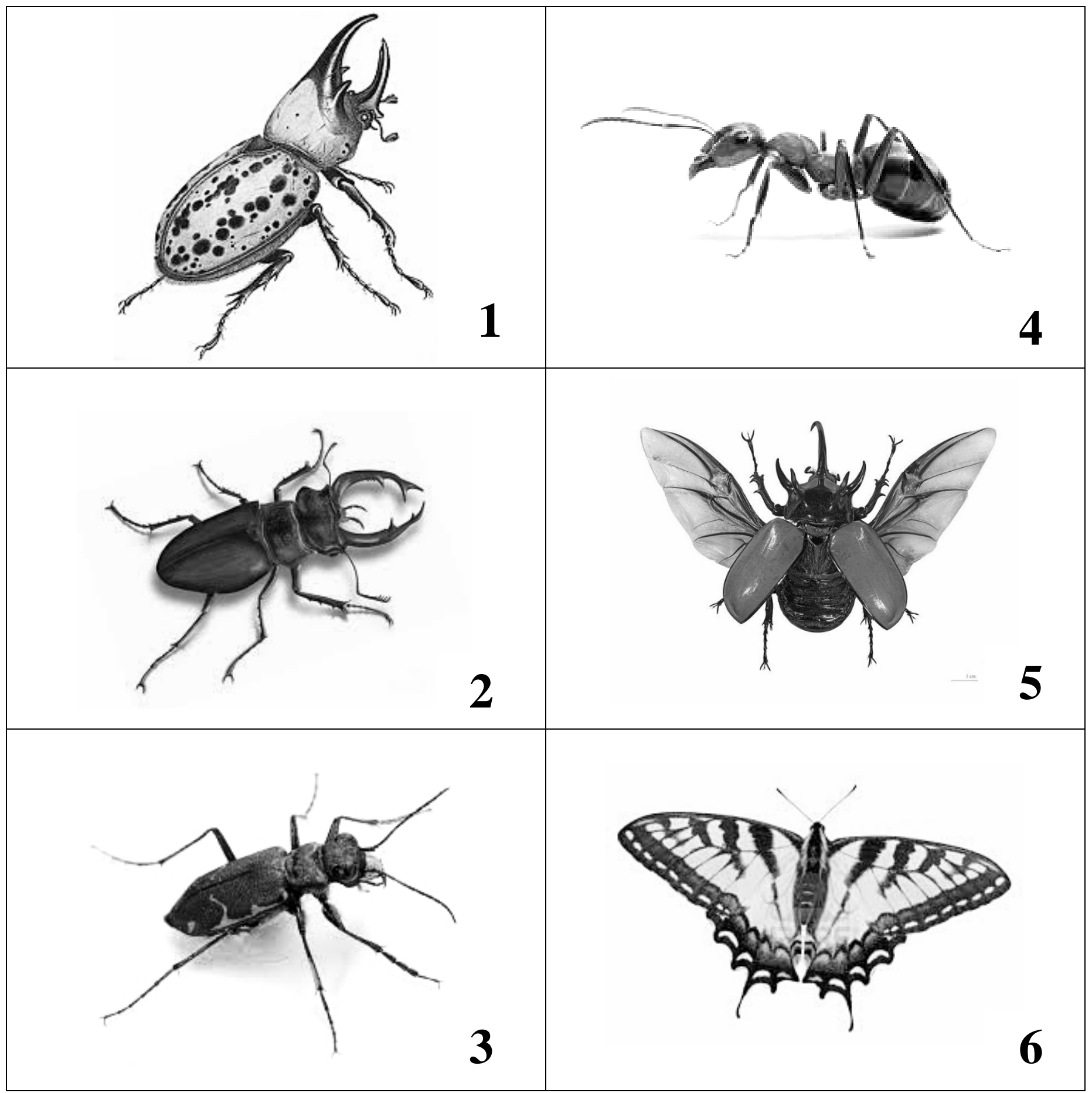

Figure 3. Examples of insect picture cards used in the life science assessment activity 


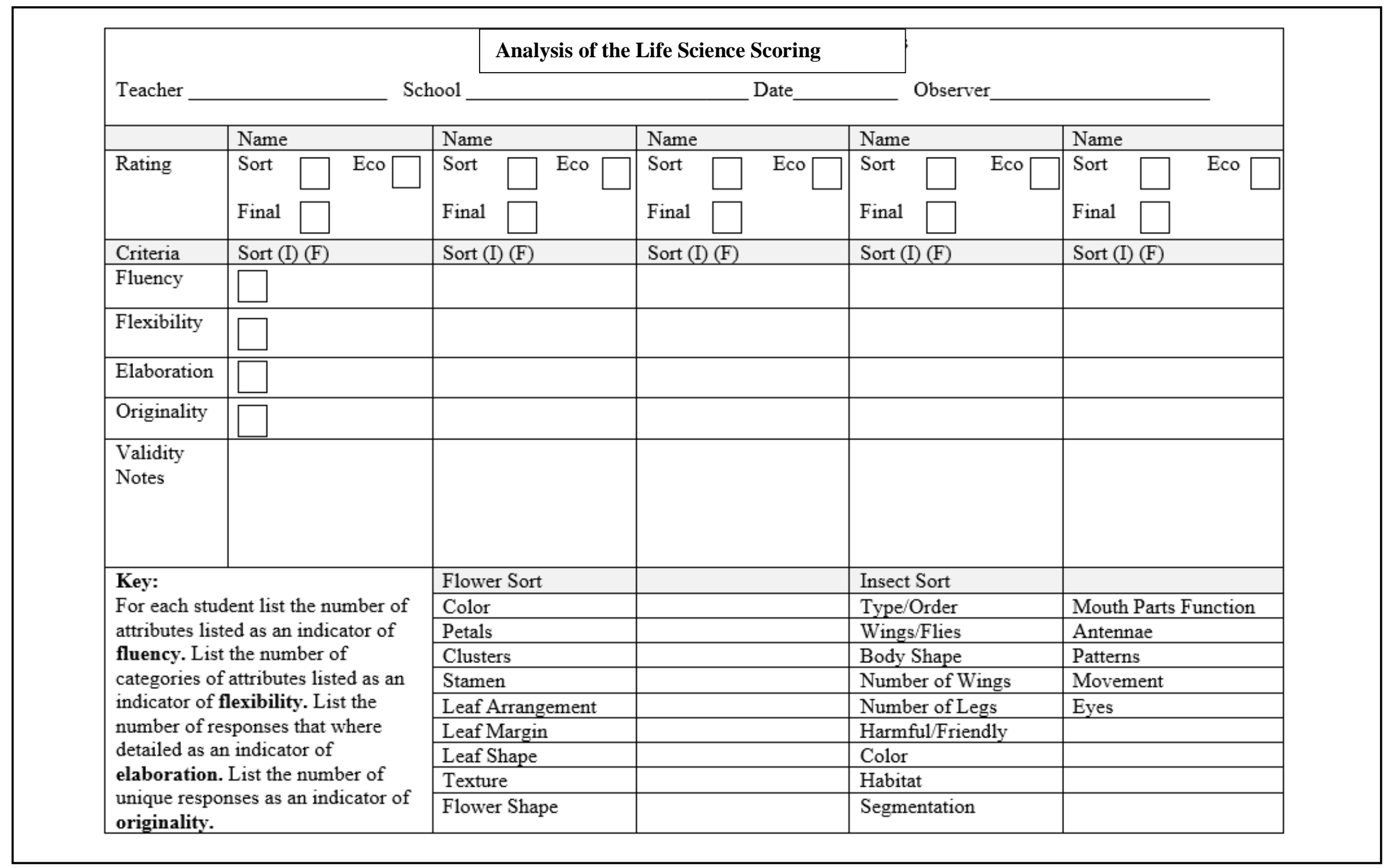

Figure 4. Worksheet for the Analysis of Life Science Scoring 

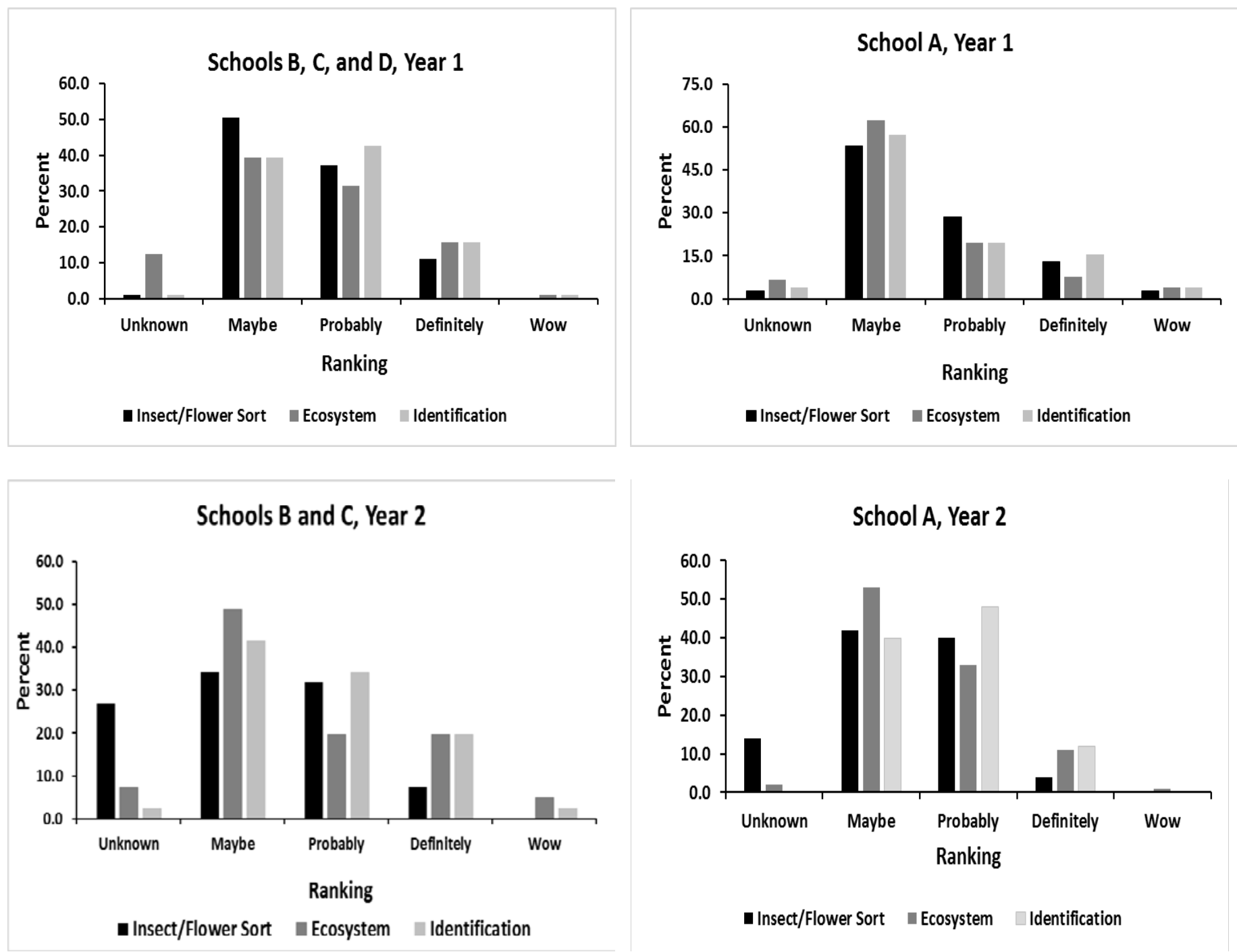

Figure 5. Ratings of Life Science Assessments (percent) for the Insect/Flower Sort, Ecosystems, and Identification for students in partner schools 
nump

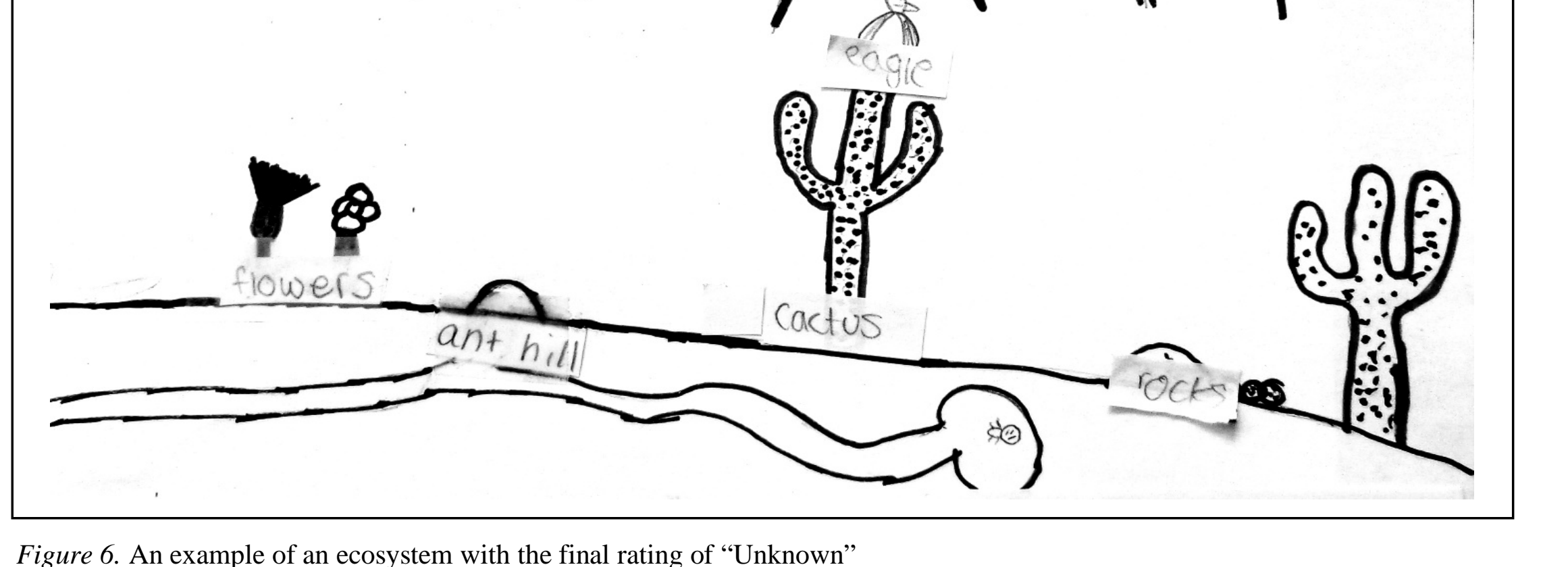




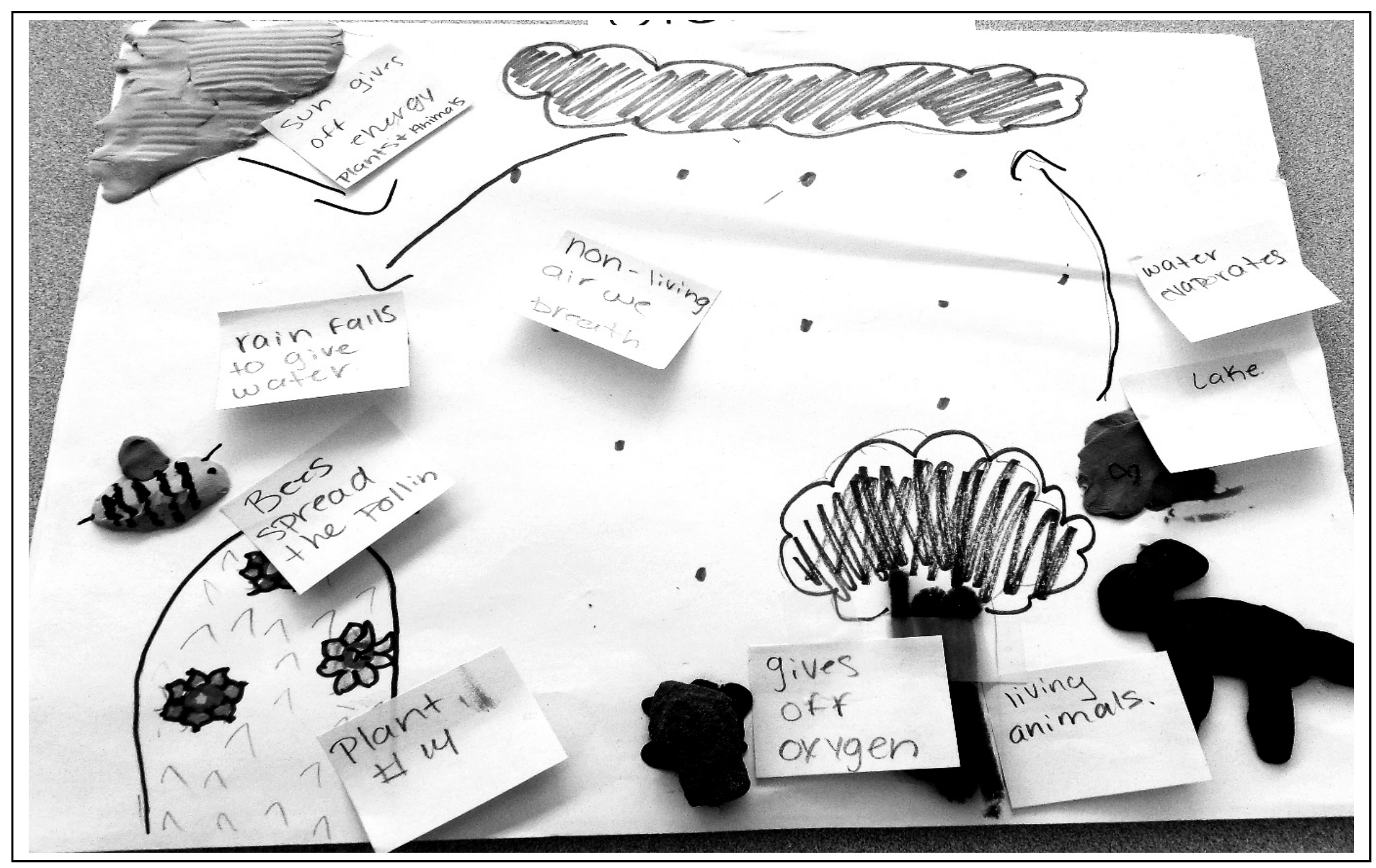

Figure 7. An example of an ecosystem with the final rating of "Probably" 


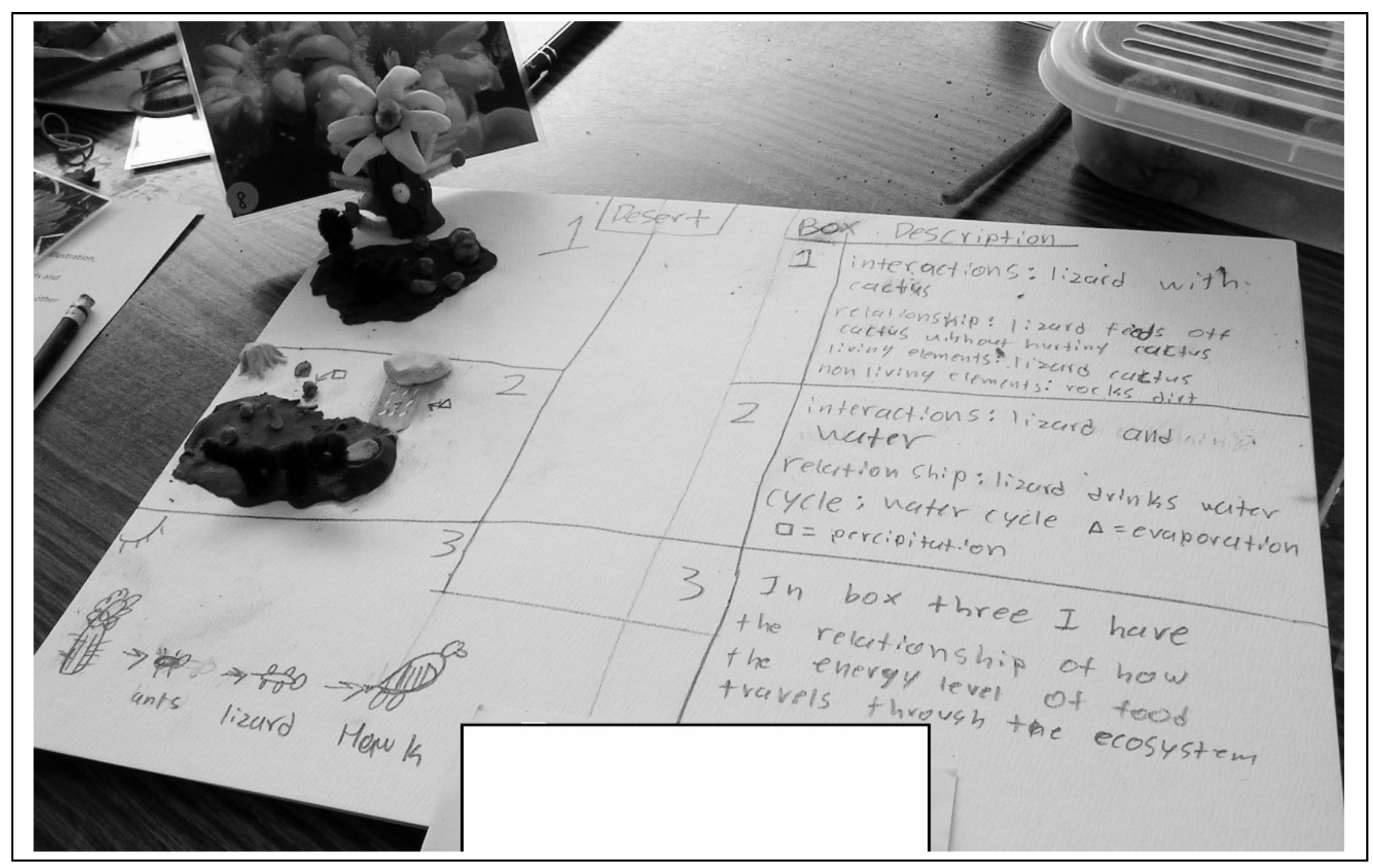

Figure 8. An example of an ecosystem with the final rating of "Wow" 

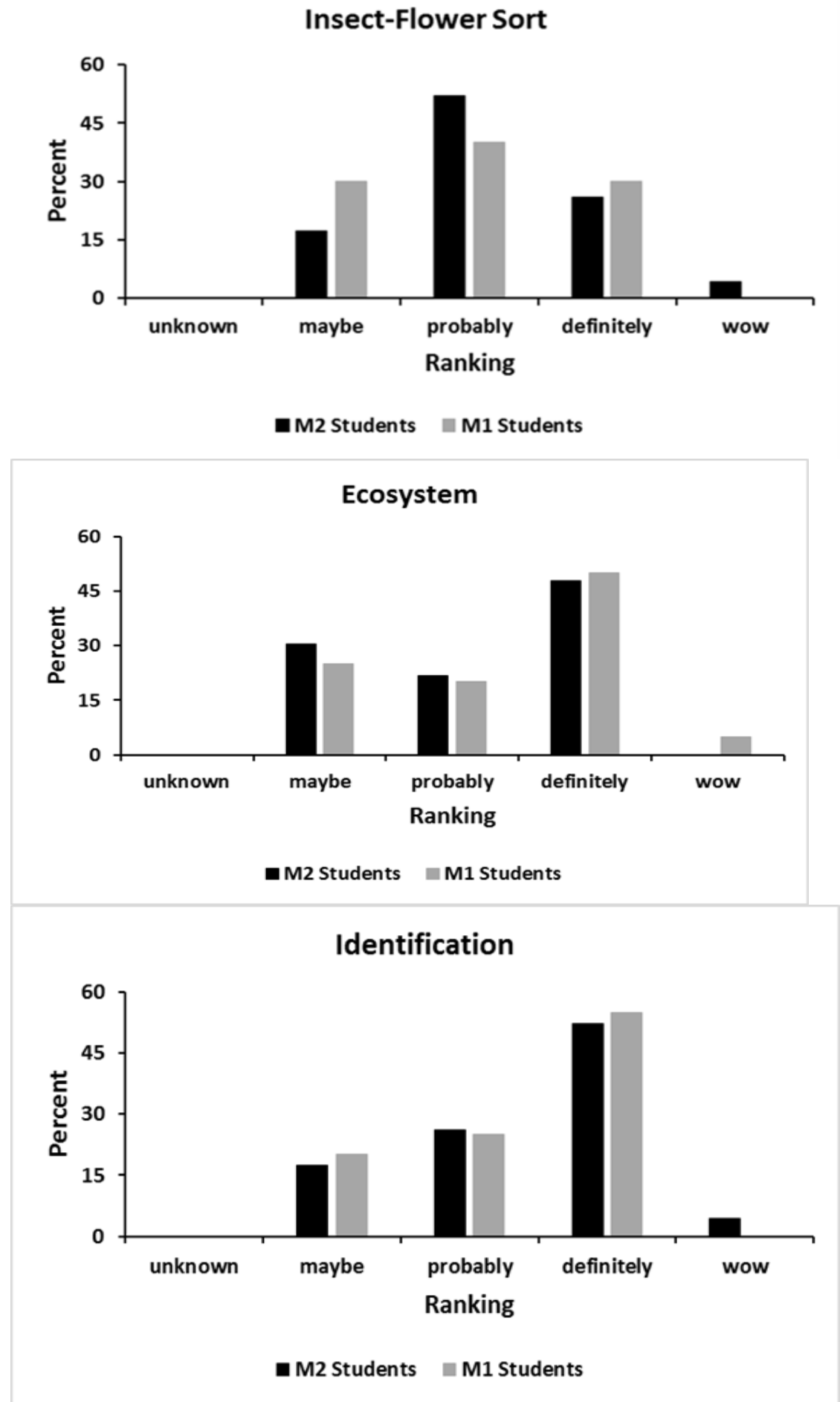

Figure 9. Comparison of scores on the Life Science Assessments for M1and M2 students 